\title{
49. Studies on Toxine of a Globefish. IV. ${ }^{1)}$
}

\author{
By Akira Yokoo. \\ Department of Chemistry, Faculty of Science, University of Okayama. \\ (Comm. by T. ShimizU, M.J.A., April 12, 1952.)
}

As described in the former paper the author obtained a crystalline poison from the ovaries of spheroides rubripes, and named it " Spheroidine."

The above paper has shown that the poison was extracted from the ovaries of spheroides rubripes with water. From the extracts, the poison was precipitated with lead acetate and ammonia. By adding phosphotungstic acid, mercury picrate, phenylhydrazine, mercury picrate, and picrolonic acid in order, the impurities were taken away. The poison was refined and crystallized by adsorption on alumina. The author, however, recently obtained a greater amount of its samples, with which he has made more accurate experiments. The results have proved that the above value was a mistake and the correct minimum lethal dose by hypodermic injection for the laboratory mouse is $0.013-0.014 \mathrm{r} / \mathrm{g}$. The analysis has also made it clear that the substance is of $\mathrm{N} 11.64 \%$ but does not contain any ash or sulpher. In recent researches the author has found that poison, which was obtained by precipitating with lead acetate and ammonia, can be adsorbed on alumina and eluted with hot water. From the eluted solution the crystalline poison can be obtained more easily than before. The minimum lethal dose of this crystalline poison is the same to the above-mentioned one. The molecular weight of this crystalline poison, "Spheroidine", by the depression of the freezing point of water is 335 . On a basis of analysis, the author considers "Spheroidine" to have the formula $\mathrm{C}_{12} \mathrm{H}_{17} \mathrm{O}_{10} \mathrm{~N}_{3}$. Through titration "Spheroidine", $\mathrm{C}_{12} \mathrm{H}_{17} \mathrm{O}_{10} \mathrm{~N}_{3}$, is proved that it has one basic group and one lactone in it. This lactone ring has a poisonous property. But when the lactone is opened, the poisonous property will be perished.

\section{Experimental.}

The original poison is extracted with water from the ovaries of globefish, (Spheroides rubripes). The extracts are evaporated under reduced pressure on the steam bath. $500 \mathrm{~g}$. of the residuary solid is dissolved in 6 liters of water, then added $300 \mathrm{~g}$. of lead acetate and filtered. To the filtrate is added $700 \mathrm{~g}$. of lead acetate, and then added 2 liters of concentrated ammonia with stirring. The precipitate is filtered with a suction and washed completely with water. 
To the washed precipitate are added 3.5 liters of water and $350 \mathrm{~g}$. of glacial acetic acid. The resultant solution is passed hydrogen sulfide through and then is filtered. The filtrated solution is evaporated on the steam bath under reduced pressure into a solid. The yield is $85 \mathrm{~g}$. The minimum lethal dose of this poison by hypodermic injection for the laboratory mouse is $10 \mathrm{r} / \mathrm{g}$.

Next a $5 \times 35 \mathrm{~cm}$. glass column is packed with $250 \mathrm{~g}$. of alumina (Merck's alumina standardized for chromatographic adsorption according to Brockmann) and then the filling is washed by passing $250 \mathrm{cc}$. of water through. The solution of $20 \mathrm{~g}$. of the above poison (M.L.D. $10 \mathrm{r} / \mathrm{g}$.) in 400 ce. of water is passed through the previously washed column of alumina. The column is washed by passing $400 \mathrm{cc}$. of water through. The adsorped poison is eluted with 3 liters of hot water. The eluted solution is acidified with acetic acid and then evaporated on the steam bath into a syrupy body. The residuary syrup is dissolved in $80 \mathrm{cc}$. of 80 vol. $\%$ methanol and then filtered. The filtrate is again evaporated on the steam bath under reduced pressure into a syrupy body. To the syrup are added 2 cc. of water and $20 \mathrm{cc}$. of methanol. To the resultant solution is added $80 \mathrm{cc}$. of ether. The precipitate of the poison is decanted and then dried over sulfuric acid in a vacuum desiccator. The yield is about $1400 \mathrm{mg}$. The minimum lethal dose for the laboratory mouse is about $0.7 \mathrm{r} / \mathrm{g}$. To the above yield of the dried poison is added $2 \mathrm{cc}$. of "water and made alkaline with ammonia. The solution is left alone for an hour. Then the poison is crystallized of itself. The white crystals of the poison are filtered with a suction and washed five times each with 1 ce. of water, two times each with 1 cc. of methanol. The crystals are dissolved in $0.5 \mathrm{cc}$. of water with a small amount of acetic acid and again filtered and washed with 10 cc. of methanol. To the filtrate is added 30 cc. of ether. The mixture is left alone for one day. Then it is again crystallized of itself. The white crystals of the poison are filtered with a suction and washed five times eath with 1 cc. of water, then two times each with 1 cc. of methanol. Next the crystals pass the same process once again to be recrystallized. The yield is about $16 \mathrm{mg}$.

Anal. Caled. for $\mathrm{C}_{12} \mathrm{H}_{17} \mathrm{O}_{10} \mathrm{~N}_{3}$ : C, 39.65; $\mathrm{H}, 4.72 ; \mathrm{N}, 11.57$.

Found : C, 39.80, 39.49, 40.08; H, 5.23, 4.89, 5.48 ; $\mathrm{N}, 11.73,12.07,11.89$.

Molecular Weight :-A definite quantity of Spheroidine is dissolved in a minimum amount of water and acetic acid. The solution is dried over sulfuric acid in a vacuum desiccator and again dried in vacuum at $130^{\circ}$ until the weight becomes constant.

Found : Spheroidine, 0.0452 g.; $\mathrm{H}_{2} \mathrm{O}, 3.517 \mathrm{~g}$.; The depression of the freezing point of water, $0.071^{\circ}$; M., 335. Caled. for $\mathrm{C}_{12} \mathrm{H}_{17} \mathrm{O}_{10} \mathrm{~N}_{3}$ : 
363.14. Titration of Basic group :-Each of $10.167 \mathrm{mg}$. and $4.289 \mathrm{mg}$. of Spheroidine dissolved in $0.0118 \mathrm{~N}$ hydrochloric acid, was titrated with $0.02724 \mathrm{~N}$ sodium hydroxide accompanied with methyl red as an indicator. The equivalent weights were found to be 364 and 350 respectively. Titration of Lactone :-Both solution resulted from the above titration of basic group were neutralized by sodium hydroxide with phenolphthalein as an indicator. To the solutions were added $7.232 \mathrm{cc}$. and $5.799 \mathrm{cc}$. of $0.02724 \mathrm{~N}$ sodium hydroxide respectively, and both solutions were left as they were for seven days. Then each solution was titrated with $0.0118 \mathrm{~N}$ hydrochloric acid. The respective equivalent weights were 365 and 355 .

\section{Reference.}

1) III : J. Chem. Soc. Japan. 71, 590 (1950). 